\title{
LIFE CYCLE AND COHORT PRODUCTIVITY IN ECONOMIC RESEARCH: THE CASE OF GERMANY
}

\author{
MICHAEL RAUBER \\ HEINRICH W. URSPRUNG
}

CESIFO WORKING PAPER NO. 2093

CATEgORY 2: PUBliC CHOICE

SEPTEMBER 2007

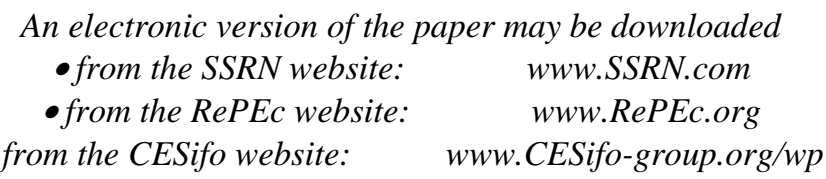




\title{
LIFE CYCLE AND COHORT PRODUCTIVITY IN ECONOMIC RESEARCH: THE CASE OF GERMANY
}

\begin{abstract}
We examine the research productivity of German academic economists over their life cycles. It turns out that the career-patterns of research productivity as measured by journal publications are characterized by marked cohort effects. Moreover, the life-cycles of younger German economists are hump-shaped and closely resemble the life cycles identified for U.S. economists, whereas the life-cycles of older German economists are much flatter. Finally, we find that not only productivity, but also research quality follows distinct life cycles. Our study employs econometric techniques that are likely to produce estimates that are more trustworthy than previous estimates.
\end{abstract}

JEL Code: A14, J24.

Keywords: research productivity, life cycles, cohort effects.

\author{
Michael Rauber \\ Department of Economics \\ University of Konstanz \\ Box D-138 \\ 78457 Konstanz \\ Germany \\ Michael.Rauber@uni-konstanz.de
}

Heinrich W. Ursprung

Department of Economics

University of Konstanz

Box D-138

78457 Konstanz

Germany

Heinrich.Ursprung@uni-konstanz.de

\section{August 2007}

We thank Christian Dustmann, Peter Egger, Bernd Fitzenberger, Werner Güth, Dean Jolliffe, Markus Jochman, Norman Lorenz, Ingmar Nolte, Paula Stephan and participants at the UCL Lunch Seminar for discussion and helpful comments, and Robert Hofmeister and Frieder Mokinski for valuable research assistance. 


\section{Life Cycle and Cohort Productivity in Economic Research: \\ The case of Germany}

\section{Introduction}

The science system in general and the economics profession in particular have in recent years become subjects of economic inquiry. Stephan (1996) surveys the economics of science literature of the first generation, and a survey summarizing the current literature dealing with the economics profession is to be found in Coupé (2004). Among the aspects that have received a great deal of attention are the methods of measuring research output, the identification of the determinants of research productivity, and the analysis of the job market consequences of research success. ${ }^{1}$

As far as the job market consequences of research success are concerned, the available literature clearly indicates that research productivity as measured by publications and/or citations is a crucial determinant of salary (see, for example, Kenny and Studley, 1996, and Moore et al., 2001), tenure and academic rank (see Coupé et al., 2006), and the obtainable job status in terms of the employing university's reputation (see Grimes and Register, 1997, and Coupé et al., 2006). When it comes to identifying and explaining the pattern of research productivity over career time, the empirical evidence becomes less clear-cut. Human capital theory suggests a hump-shaped progression of individual research productivity since the stock of human capital (which drives high productivity) needs to be built up at the beginning of the career, and obsolescence of knowledge is likely to dominate the positive effect of increased experience towards the

\footnotetext{
${ }^{1}$ Even though these lines of investigation are, of course, related to the plethora of existing research evaluations, they are in no way contaminated with the allegations levelled against the value and significance of research evaluations as expressed, for example, by Frey (2007).
} 
end of professional life. ${ }^{2}$ A standard hump-shaped research productivity curve indeed emerges in some empirical studies investigating professional economists (see Kenny and Studley, 1996, Oster and Hamermesh, 1998, and Baser and Pema, 2004). It is, however, conceivable that the identified hump-shape represents an artifact of the quadratic specification of elapsed career time in the employed regressions of research productivity. Goodwin and Sauer (1995) identify a more complex career productivity profile that follows a fifth degree polynomial, whereas evidence uncovered by Hutchinson and Zivney (1995) and Hartley et al. (2001) do not indicate any significant decline in productivity as experience increases - a result that is compatible with the view that research behavior, rather than being determined by human capital considerations, can be explained by sociological factors related to social imprinting.

The social imprinting hypothesis suggests that significant variations in research behavior may be observed when comparing different cohorts of researchers. So far, however, the empirical studies have not uncovered strong cohort effects in the economics profession: Basar and Pema (2004) do not find any cohort effects at all, and Goodwin and Sauer (1995) report only marginally significant effects which, however, may well reflect the fact that the members of the analyzed cohorts differ in age, implying that the older cohorts are composed of academic survivors who are likely to have been more productive on the average. Notice also that the hitherto available empirical evidence relates to the United States; studies relating to countries whose academic institutions were subject to major recent changes may exhibit substantially different cohort effects.

One of the objectives of our paper is to analyze how the traditional continental European science system has responded, on the one hand, to structural changes that

\footnotetext{
${ }^{2}$ For a survey of the literature dealing with how life cycle productivity changes in response to changes in cognitive abilities, see Skirbekk (2004).
} 
provide more incentives for high research productivity, and, on the other hand, to the increased competition stemming from the fact that the European science system has become more and more exposed to the global standards set by the Anglo-Saxon system. We analyze this transformation process by scrutinizing the research behavior of different cohorts of scientists. For this purpose, the German economics profession appears to represent a very suitable example because in a large country such as Germany international competition was little noticed before the onset of European economic and political integration. Moreover, the German economic profession has for a long time been dominated by an idiosyncratic approach (the so-called historical school) that virtually decoupled the German profession from the emerging mainstream of economic research. The initial position of the German profession has thus been quite far removed from the mainstream. Moreover, the onset of the transition is reasonably close to the time period for which empirical evidence is available. Considering, finally, the success of the youngest batch of German economists in the global academic labor market, one can argue that the transition process is now coming to an end, implying that we can capture a substantial part of the whole adjustment process.

In this study we measure research output with the help of publications. There is general agreement that publications need to be adjusted for quality if they are used as indicators of research productivity. Two ways of controlling for publication quality have been employed in the literature: some scholars (for example Goodwin and Sauer, 1995) restrict themselves to articles published in a select list of highly reputable journals, whereas others (for example Kenny and Studley, 1996, and Coupé et al., 2006) base their measure of research productivity on a more encompassing list of journals and use explicit quality weights that are based on the respective journals' scientific impact. Hybrid 
approaches with two or more quality classes of journals are also quite common (see, for example, Grimes and Register, 1997, Oster and Hamermesh, 1998, and Moore et al., 2001).

Since research productivity consists of a quantity and a quality component, the identified career patterns can, in principle, be decomposed into a quantity and a quality cycle if the quality range of the considered journals is not overly restricted. Particularly interesting insights from quality-quantity decompositions refer to heterogeneity in research ability. It transpires that quality publishers are in general also quantity publishers (see Hutchinson and Zivney, 1995) and that the post-peak decline of the most prolific economists is much smaller than the decline of the less productive economists (see Grimes and Register, 1997). Oster and Hamermesh (1998) show that top producers keep on producing high-quality research, but at a slower rate, whereas the slowdown of second-rate economists leads them to publish in lower quality outlets. Truly creative economics at the highest level is, however, mainly undertaken by the young (see Oster and Hamermesh, 1998, and van Dalen, 1999).

A related strand of the literature investigates the impact of institutional features on the pattern of research productivity. Of special interest are the influence of entry barriers (such as the institution of the "habilitation" which is still exercised in some continental European countries), mid-career hurdles such as tenure and rank promotions, and also institutional provisions that affect the mobility of academic researchers between universities. ${ }^{3}$ Entry and promotion barriers have typically been portrayed as contests

\footnotetext{
${ }^{3}$ Such provisions can either be designed to restrain mobility (examples are lock-ins via retirement benefits and German-type cartel agreements among university presidents or their superiors in the respective governments) or to increase mobility (international mobility of researchers is promoted, for example, with the help of the Marie Curie Actions organized and financed by the European Commission).
} 
designed to induce higher research effort via increased competition (see Backes-Gellner and Schlinghoff, 2004, Coupé et al., 2003, and Dnes and Garoupa, 2005). The empirical evidence indicates that these institutional provisions do indeed work as incentive schemes and thus influence the pattern of research productivity: those life-cycle studies that identify hump-shaped productivity patterns usually find that research productivity peaks about six years into the professional career, i.e. around the time when professors can apply for tenure. The post-tenure decline in productivity appears however to be rather small (see Bell and Seater, 1978, and Hutchinson and Zivney, 1995). Somewhat more informative results emerge from micro-econometric studies using information about when exactly the individual researchers were promoted: Backes-Gellner and Schlinghoff (2005) uncover strong evidence for the United States and Germany indicating that promotion tournaments give rise to an increase in research productivity before promotion and a lapse of productivity afterwards. Moreover, they show that the career profiles of German economists is characterized by a more pronounced post-tenure decline than the profiles of their American colleagues, the reason being that the German university system lacks a second career step, namely promotion to full professor. Analyzing publication records of 650 economists who are members of the top-1000 group according to a worldwide ranking, Coupé et al. (2006) corroborate the result that promotions cause cyclical deflections in research productivity: pre-promoted economists are more productive than post-promoted ones, and tenure has an additional negative effect on research productivity.

The focus of our study is however not on the institutional features of the German academic labor market. We rather treat career steps as an endogenous to academic careers and relate individual research productivity to career age. The paper unfolds as follows. In section 2 we describe our data set and in section 3 we present our base-line estimates of 
the life cycles in research productivity. We identify life cycles that are akin to, but rather flatter than the life cycles of American economists uncovered by Goodwin and Sauer (1995). Moreover, we arrive at the result that the German profession is characterized by significant cohort effects in research productivity. We also find that the shape of the life cycles depends on the individual researchers' ability. Studies focusing on aggregates thus miss an essential part of the story that relates to heterogeneity. In section 4 we then go on to investigate cycles in the constituent parts (quantity, quality, number of co-authors) of our measure of research productivity. Section 6 concludes.

\section{The Data}

\subsection{The sample}

Whereas many other bibliometric studies focus on researchers who publish frequently, our dataset compromises, in principle, all German academic economists. Our dataset encompasses 699 economists who received their doctoral degrees between 1963 and 1998 and who were employed by a German university in the year 2004 or had retired from a German university briefly before. ${ }^{4}$ The youngest economists in our sample thus have a minimum of six years of post-Ph.D. experience.

Our study relies on the EconLit data base that contains journal publication records from 1969 onwards. In choosing the starting year of 1963 we thus lose only the first six years of the 1963-1968 cohort. We measure research output exclusively on the basis of the journal literature. This admittedly neglects other types of research outlets such as monographs and articles published in collected volumes and proceedings. We are,

\footnotetext{
${ }^{4}$ We gathered information on more than one thousand German economist. Our sample comprises however only those economists who obtained their doctoral degree after 1962 and for whom we could actually establish the exact year in which they obtained their doctoral degree.
} 
however, in accord with most scholars in the field who are confident that EconLit indexes the most important journals of the economics profession and that the articles published in these journals together constitute the lion's share of economic research (see, for example, Hartley et al., 2001, Combes and Linnemer, 2003, and Coupé, 2003).

We collected all EconLit-listed journal publications authored or co-authored by the economists included in our sample up to the year 2004 and linked the annual records to the year in which the author obtained his or her doctoral degree. ${ }^{5}$ We were thus able to establish individual life cycles of research productivity for a large number of German economists. These life cycles represent the basic input for our empirical analysis.

Only 7 percent of the 699 economists in our sample are women. Fourteen percent specialize in microeconomics, 27 percent in macroeconomics and international economics, 35 percent in public economics and 16 percent in econometrics. Economists who could not be assigned to one of these fields were assigned to the field OTHER. Interestingly, 94 or about 13 percent of the economists in our sample have never published in an EconLit-listed journal.

\subsection{The dependent variable: Individual annual research productivity}

EconLit indexes these days over 800 journals. It is quite evident that the quality standards set by these journals are quite diverse. As a consequence, publication-based bibliometric measures need to control for journal quality. This can be done by restricting the set of journals. We do, however, not believe that this is a viable strategy of measuring research output because a robust research indicator needs to draw on all available information. Using, for example, only a relatively small number of top-journals would bias the

\footnotetext{
${ }^{5}$ Whenever EconLit reported "et al.” we identified the hidden co-authors by tracing the article.
} 
indicator in favor of top-researchers specializing in hot topics. Moreover, life cycle patterns in research quality (as compared to cycles in overall output) can only be properly identified if the whole quality range of research products is taken into account.

To control for the quality of the journals indexed in EconLit we settled for a standard method proposed by Combes and Linnemer (2003). ${ }^{6}$ Their “CLpn” scheme weighs quality according to the respective journal's reputation and impact, and converts research output in standardized units of AER-page equivalents by also taking into account the number (p) of pages and the number (n) of co-authors. The imputed quality weights lie between unity for top journals and one twelfth for journals with the lowest quality standards. The top-tiered journals are the American Economic Review, Econometrica, the Journal of Political Economy, the Quarterly Journal of Economics and the Review of Economic Studies. Sixteen journals receive a weight of two thirds. Weights then decline in discrete steps (one half, one third, one sixth) down to the minimum weight of one twelfth.

To construct our dependent variable, the number of pages of each article is multiplied by the respective CL journal weight and this product is then divided by the number of authors. Adding the scores calculated according to this rule over all articles published by researcher i in year t, we arrive at our basic research productivity measure. To check for the robustness of our results, we have, however, also used an alternative journal-quality weighting scheme. We will explicitly refer to this robustness check when we discuss the respective results.

\footnotetext{
${ }^{6}$ One disadvantage of using the CLpn scheme is that journal quality is kept constant over the period of investigation that covers, after all, a time-span of 36 years. Since, however, journal rankings exhibit a great deal of persistence (see, for example, Sutter and Kocher, 2001) and we assign journals to a small number of quality classes, changes in journal quality are not likely to cause severe problems.
} 


\subsection{The explaining variables}

To identify life cycle patterns in individual research productivity we regress our dependent variable, research productivity of researcher i at time t, on several independent variables, the most important one being experience or career-time.

\section{Experience}

In accordance with the literature we align all individual life cycles by using as the reference year the year in which the researchers obtained their doctoral degrees. In our regressions we do, however, also include the research output generated in the pre-Ph.D. years by letting the life cycles begins five years before the reference year zero. To estimate the shape of the lifecycles we include career-time polynomials of different orders in the regressions. Simple t-tests as well as likelihood ratio-tests were used to determine the optimal degree of the polynomial. In most cases a $5^{\text {th }}$ degree polynomial has proven to fit the data best. ${ }^{7}$

\section{Individual heterogeneity}

It cannot be ruled out that publication habits vary across different fields of research. A simple comparison of the average yearly per capita research productivity across different fields reveals that this conjecture cannot be easily dismissed: these productivities range between 2.04 AER-equivalent pages in microeconomics and 0.42 AER-equivalent pages in our remainder group OTHER. We decided therefore to include the field of research as a dummy variable to allow for different research cultures across fields. A second reason for including field dummies is that these variables would also capture any bias stemming

\footnotetext{
${ }^{7}$ Goodwin and Sauer (1995) come to a similar conclusion using their data on US economists.
} 
from an uneven coverage of the research fields in the EconLit data base as a whole and/or within each quality-group of journals. The interpretation of field-specific effects on research productivity is therefore not straight-forward.

The gender issue has for a long time played a major role in labor economics and has, as a consequence, been taken up also in several studies of research productivity. We follow this tradition and include a gender variable that may capture gender specific differences in research productivity.

\section{Cohorts and historical time}

Research productivity may not only vary across different fields of economic research but also across historical time. To allow for vintage effects we include cohort dummy variables in our specification. They are constructed by using the reference year in which the researchers obtained their doctoral degrees, starting in 1963.

A second possibility is to include a time trend in the regressions. Just as cohort dummies, a time trend will capture changes of research behavior across historical time. Whereas cohort dummies portray changes in research behavior that are peer-group specific (they could, for example, portray different cultural imprinting patterns across time), a time trend indicates that individual research productivity does change over time for all researchers and this change is independent of experience. Such time trends might capture changes in publication customs, for example a substitution away from monographs and collected volumes towards journals. Unfortunately, a separate identification of linear cohort effects and a linear time-trend appears not to be possible since the difference between historical time and career age is used to assign the individual researcher to a cohort. Imposing specific functional forms to separate the two effects 
appears to be a rather dubious strategy because there are no obvious restrictions that could be imposed. ${ }^{8}$ In the following section we therefore present first our regression results that do not control for historical time effects, and then deal with the historical time problem explicitly in the subsection 3.2.

\section{Results}

\subsection{Identifying life cycles in research productivity}

The set of explaining variables of our base-line lifecycle regressions consists of a career time polynomial, the cohort dummies, the gender dummy, the field dummies and a constant. The dependent variable $\mathrm{Y}_{\text {it }}$ represents individual i's research productivity as measured by our productivity index at career-time t. Because of the high degree of censoring (about $3 / 4$ of our Y-observations are zeroes) we cannot apply OLS and have to rely on techniques which can properly accommodate heavily censored data sets. The results are summarized in Table I:

\footnotetext{
${ }^{8}$ Different restrictions and even small specification errors might have large effects on the estimates. For a discussion see Rodgers (1982). By including a time trend in addition to our cohort dummies we therefore would not gain much additional insights since the estimated effects would solely depend on the underlying functional forms and should therefore not be interpreted.
} 


\begin{tabular}{|c|c|c|c|c|c|}
\hline \multirow[t]{2}{*}{ Table I } & \multirow[b]{2}{*}{ Tobit } & \multicolumn{4}{|c|}{ Hurdle Model } \\
\hline & & $\begin{array}{c}\text { Conditional } \\
\text { Exponential Mean } \\
\text { (NLS) }\end{array}$ & Probability & Cond. Mean & $\begin{array}{l}\text { Tobit } \\
\text { Kalaitzidakis weights }\end{array}$ \\
\hline $\mathrm{T}$ & $\begin{array}{l}1.9989 * * * \\
(17.12)\end{array}$ & $\begin{array}{l}0.6394 * * * \\
(11.26)\end{array}$ & $\begin{array}{l}0.3885^{* * * *} \\
(19.23)\end{array}$ & $\begin{array}{l}0.1819 * * * \\
(7.28)\end{array}$ & $\begin{array}{l}93.952 * * * \\
(10.16)\end{array}$ \\
\hline $\mathrm{T}^{2} / 10$ & $\begin{array}{l}-2.413^{* * *} \\
(11.40)\end{array}$ & $\begin{array}{l}-0.9498 * * * \\
(9.58)\end{array}$ & $\begin{array}{l}-0.5097 * * * \\
(13.07)\end{array}$ & $\begin{array}{l}-0.2608^{* * * *} \\
(5.37)\end{array}$ & $\begin{array}{l}-124.101^{* * *} \\
(8.20)\end{array}$ \\
\hline $\mathrm{T}^{3} / 100$ & $\begin{array}{l}1.2635^{* * * *} \\
(7.76)\end{array}$ & $\begin{array}{l}0.5809^{* * *} \\
(8.25)\end{array}$ & $\begin{array}{l}0.2908^{* * * *} \\
(9.47)\end{array}$ & $\begin{array}{l}0.1519 * * * \\
(3.90)\end{array}$ & $\begin{array}{l}70.560 * * * \\
(6.44)\end{array}$ \\
\hline $\mathrm{T}^{4} / 1000$ & $\begin{array}{l}-0.2989 * * * \\
(5.61)\end{array}$ & $\begin{array}{l}-0.1550^{* * *} \\
(7.19)\end{array}$ & $\begin{array}{l}-0.0746^{* * * *} \\
(7.34)\end{array}$ & $\begin{array}{l}-0.0386^{* * *} \\
(2.93)\end{array}$ & $\begin{array}{l}-18.142^{* * *} \\
(5.20)\end{array}$ \\
\hline $\mathrm{T}^{5} / 10000$ & $\begin{array}{l}0.0260^{* * * *} \\
(4.22)\end{array}$ & $\begin{array}{l}0.0149 * * * \\
(6.31)\end{array}$ & $\begin{array}{l}0.0070^{* * *} \\
(5.96)\end{array}$ & $\begin{array}{l}0.0035^{* *} \\
(2.26)\end{array}$ & $\begin{array}{l}1.7090 * * * \\
(4.30)\end{array}$ \\
\hline C6974 & $\begin{array}{l}0.6744 \\
(0.76)\end{array}$ & $\begin{array}{r}0.0874 \\
(0.31)\end{array}$ & $\begin{array}{l}0.1945 \\
(1.18)\end{array}$ & $\begin{array}{c}-0.1704 \\
(1.17)\end{array}$ & $\begin{array}{c}-7.5984 \\
(0.15)\end{array}$ \\
\hline C7580 & $\begin{array}{l}3.1352^{* * *} \\
(3.12)\end{array}$ & $\begin{array}{l}0.4203 \\
(1.55)\end{array}$ & $\begin{array}{l}0.5938^{* * *} \\
(3.44)\end{array}$ & $\begin{array}{l}0.0202 \\
(0.13)\end{array}$ & $\begin{array}{l}106.020^{*} \\
(1.90)\end{array}$ \\
\hline C8186 & $\begin{array}{l}5.3574 * * * \\
(5.23)\end{array}$ & $\begin{array}{l}0.9202^{* * *} \\
(3.48)\end{array}$ & $\begin{array}{l}1.0030^{* * *} \\
(5.68)\end{array}$ & $\begin{array}{l}0.1052 \\
(0.72)\end{array}$ & $\begin{array}{l}213.806^{* * *} \\
(3.62)\end{array}$ \\
\hline C8792 & $\begin{array}{l}6.9861 * * * \\
(7.74)\end{array}$ & $\begin{array}{l}1.1961^{* * *} \\
(4.88)\end{array}$ & $\begin{array}{l}1.2231^{* * *} \\
(7.80)\end{array}$ & $\begin{array}{l}0.2166 \\
(1.63)\end{array}$ & $\begin{array}{l}276.024 * * * \\
(5.16)\end{array}$ \\
\hline C9398 & $\begin{array}{l}8.5998^{* * *} \\
(9.89)\end{array}$ & $\begin{array}{l}1.3649 * * * \\
(5.79)\end{array}$ & $\begin{array}{l}1.4860^{* * *} \\
(9.43)\end{array}$ & $\begin{array}{l}0.2883^{* *} \\
(2.39)\end{array}$ & $\begin{array}{l}325.609 * * * \\
(6.42)\end{array}$ \\
\hline MICRO & $\begin{array}{l}8.0980^{* * *} \\
(6.52)\end{array}$ & $\begin{array}{l}1.3866^{* * *} \\
(5.05)\end{array}$ & $\begin{array}{l}1.3753^{* * *} \\
(6.65)\end{array}$ & $\begin{array}{l}0.4562 * * * \\
(2.78)\end{array}$ & $\begin{array}{l}512.220 * * * \\
(6.20)\end{array}$ \\
\hline MACRO & $\begin{array}{l}5.9956 * * * \\
(5.45)\end{array}$ & $\begin{array}{l}1.0372 * * * \\
(3.89)\end{array}$ & $\begin{array}{l}1.1500^{* * *} \\
(5.78)\end{array}$ & $\begin{array}{l}0.1440 \\
(0.93)\end{array}$ & $\begin{array}{l}324.030 * * * \\
(5.15)\end{array}$ \\
\hline PUBLIC ECONOMICS & $\begin{array}{l}4.8836^{* * * *} \\
(4.38)\end{array}$ & $\begin{array}{l}0.9315^{* * * *} \\
(3.46)\end{array}$ & $\begin{array}{l}0.9688^{* * * *} \\
(4.81)\end{array}$ & $\begin{array}{l}0.1329 \\
(0.85)\end{array}$ & $\begin{array}{l}273.39 ß * * * \\
(4.40)\end{array}$ \\
\hline ECONOMETRICS & $\begin{array}{l}3.6397 * * * \\
(3.07)\end{array}$ & $\begin{array}{l}0.6340^{* *} \\
(2.18)\end{array}$ & $\begin{array}{l}0.7692 * * * \\
(3.51)\end{array}$ & $\begin{array}{r}-0.0122 \\
(0.07)\end{array}$ & $\begin{array}{l}264.470^{* * *} \\
(3.87)\end{array}$ \\
\hline FEMALE & $\begin{array}{l}-3.8694 * * * \\
(4.57)\end{array}$ & $\begin{array}{l}-0.5504^{* *} \\
(2.54)\end{array}$ & $\begin{array}{l}-0.6591 * * * \\
(4.45)\end{array}$ & $\begin{array}{l}-0.1345 \\
(1.08)\end{array}$ & $\begin{array}{l}-182.122 * * * \\
(3.53)\end{array}$ \\
\hline CONSTANT & $\begin{array}{l}-18.911^{* * *} \\
(13.57)\end{array}$ & $\begin{array}{l}-2.4434^{* * * *} \\
(6.98)\end{array}$ & $\begin{array}{l}-3.6847 * * * \\
(15.64)\end{array}$ & $\begin{array}{l}3.4968 * * * \\
(18.85)\end{array}$ & $\begin{array}{l}-1098.304^{* * *} \\
(10.21)\end{array}$ \\
\hline Observations & 18610 & 18610 & 186 & & 18610 \\
\hline (Pseudo)-R² & 0.0597 & 0.1806 & & & 0.0338 \\
\hline Log Likelihood & -20229.9 & & -134 & 262.8 & -23384.8 \\
\hline
\end{tabular}

Notes: Absolute t-values in parentheses, based upon a clustering robust Variance-Covariance Matrix on individual level. $* * *$ denotes significant at the 1 percent level, $* *$ at the 5 percent level and $*$ at the 10 percent level (applies to all tables). 
In the first column we present Tobit estimates using a 5th degree polynomial for career time. Column two shows the results obtained from a model presupposing an exponential conditional mean function that is estimated via nonlinear least squares:

$$
E\left(Y_{i t} \mid x_{i t}\right)=\exp \left(x_{i t}{ }^{\prime} \beta+\varepsilon_{i t}\right) .
$$

In the following two columns we present estimates of a hurdle model. The hurdle model assumes that the decision to undertake research at all might be driven by other forces than the decision with respect to how much research effort is expended by an active researcher and is therefore parametrically richer than the Tobit model. We model the two stages of the decision making process as follows:

$$
\begin{aligned}
& \operatorname{Pr}\left(Y_{i t}=0\right)=\exp \left(-\gamma_{i t}\right) \\
& \operatorname{Pr}\left(Y_{i t}=y \mid x_{i t}, y>0\right)=\frac{\lambda_{i t}^{y}}{y !\left(1-\exp \left(-\lambda_{i t}\right)\right)} \exp \left(-\lambda_{i t}\right),
\end{aligned}
$$

where $\lambda_{i t}=\exp \left(x_{i t}{ }^{\prime} \beta\right), \quad \gamma_{i t}=\exp \left(x_{i t}{ }^{\prime} v\right)$

The occurrence of non zero counts is modeled via a Poisson probability specification and conditional output is described using a truncated Poisson density. ${ }^{9}$ The Poisson model appears to be appropriate since the observed density distribution of our dependent variable resembles the pattern of count data. This resemblance (spikes at steps of one twelfth) emerges because the CLpn-index is based on journal weights that are multiples

\footnotetext{
${ }^{9}$ We also estimated a Negative Binomial specification for the conditional output (see Pohlmeier and Ulrich, 1995, for an example of a complete NegBin hurdle specification). The resulting estimates are well in line with the estimates of the Poisson specification.
} 
of one twelfth. To arrive at proper count data we divided our dependent variable by one twelfth and rounded to the next integer. The transformed variable can then, of course, be analyzed by using a count data model in which one count can be interpreted as one twelfth of an AER-equivalent page or one page published in a journal of lowest quality. ${ }^{10}$

In the last column of Table I we present Tobit estimates if the weighting scheme of journal quality underlying the Combes and Linnemer (CL) measure of research output is replaced by the "KMS" weighting scheme proposed by Kalaitzidakis, Mamuneas and Stengos (2003) which covers only 159 Journals and gives top-journals a much larger weight than the CL scheme. The Journal of International Economics for example, the most highly regarded journal in its field, is allocated a relative weight of 2/3 (as compared to the American Economic Review) in the CL scheme, whereas it receives a relative weight vis-à-vis the AER of only about $8 \%$ in the KMS scheme.

The estimates presented in Table I are not obscenely at variance with the standard life cycle hypothesis. As can be seen from the panels in Figure 1, the estimated career-time polynomials imply in each case a hump-shaped curve of research productivity over career time. All models fit best with a life cycle polynomial of degree five which gives rise to a peak in research productivity which occurs around the eights career year, i.e. when German academic economists are usually promoted to full professor. Even though the standard life cycle hypothesis passes the test reasonably well, we do not find a marked and final decline in research productivity after the initial peak. Research productivity rather appears to remain quite constant over a substantial part of the lifecycle

\footnotetext{
${ }^{10}$ To check for the robustness of our results we additionally used $1 / 2$ and $1 / 4$ of an AER-equivalent page as count units without obtaining significantly different results. However, since the underlying density has spikes at steps of one twelfth, the applied scheme appears to be more natural and precise. As an additional robustness check of our specification we estimated a hurdle model which assumes a lognormal distribution of the positive scores of Y (see Wooldridge, 2002). The results are similar to the ones obtained from the count data hurdle model presented above.
} 
which implies that our estimates may just as well be construed to support the sociological hypothesis of imprinting.

\section{Figure 1: Pooled specification}
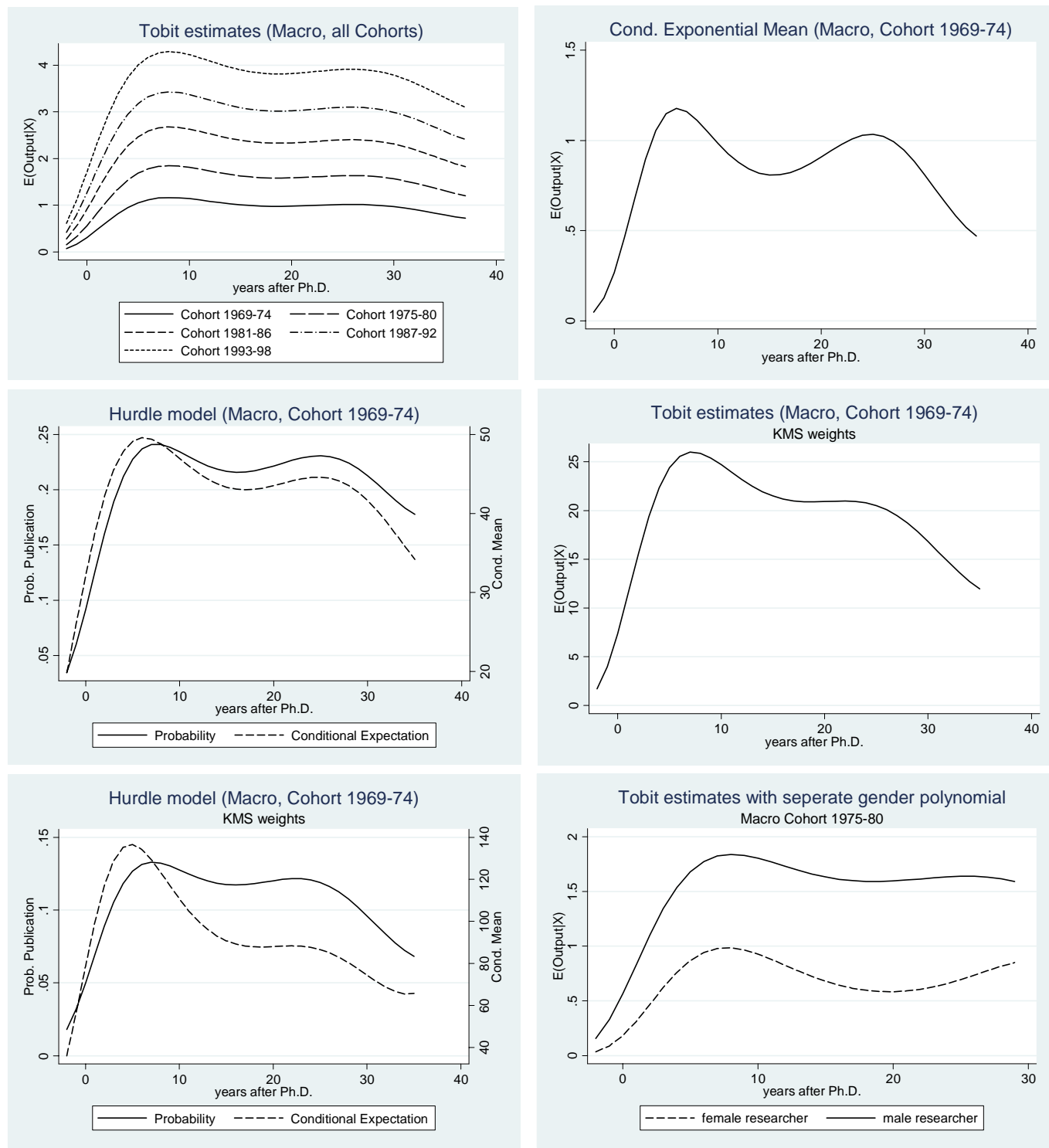

The increase in research productivity towards the end of the researchers' careers identified by both the exponential model and the hurdle model is in line with the results 
presented by Goodwin and Sauer (1995). Their estimates for American economists show however a more substantial decline in research productivity during the mid-career years. Interestingly, the hurdle specification indicates that the probability of undertaking research and conditional research output follows somewhat different time patterns.

Our estimation results documented in the first four columns of Table I do not appear to depend on the employed CL method of measuring research output. When research output is measured with the help of the KMS method, the Tobit estimates survive the robustness check with flying colors (see column 5, Table I, and Figure 1, panel 4). Also the hurdle model yields fairly similar results when the KMS measure is used (estimation results not shown); the career patterns documented in panel 5 of Figure 1 reinforce our conclusion that one can lose important information when estimating publication incidence and conditional output together. The more marked drop in the conditional output is a consequence of the more top-heavy KMS quality weighting scheme and represents a clear sign that research quality changes as the economists' careers progress. We will pursue this hypothesis further in section 4.

The coefficient of the gender dummy FEMALE indicates that female economists publish significantly less than their male peers. The hurdle model reveals however that this negative effect seems to be mainly due to the decision to engage in research activities at all rather than a consequence of a lower productivity of female economists who are active researchers. Tobit estimates of separate career time polynomials for male and female economists (estimation results not shown) show that female economists suffer a drop of research productivity beginning in their eight's career year when they are about 38 years old; they appear however to recuperate around the $18^{\text {th }}$ career year when they are about 48 years old (see Figure 1, panel 6). This well squares with the interpretation of a 
"maternal leave from research", especially if one allows for a one or even two years publication lag. ${ }^{11}$

As expected, the coefficients of the cohort dummies increase over time. ${ }^{12}$ We interpret this result to imply that members of younger cohorts are more productive researchers than their older peers. About the reasons for this phenomenon we can only speculate: the evidence certainly does not contradict the hypothesis that over the last thirty years the German economics profession has increasingly been exposed to the Anglo-Saxon research tradition that stresses the requirement to document one's research efforts on a continuous basis. Many economists who returned in the 1970s and 1980s from the UK and the US were instrumental in sharing their experience with their graduate students who internalized this research culture which nowadays characterizes the academic environment at German graduate schools and dominates the increasingly competitive hiring strategy employed by the leading departments. In order to scrutinize the determinants of the identified cohort effects, we analyze below cohort-specific lifecycles which will be more informative than the pooled life-time productivities presented so far.

Although the Tobit estimates seem to be well in line with the results of the other estimators, a test for heteroscedasticity and a Pagan and Vella (1989) conditional moment test on normality of the underlying disturbance reject the hypotheses, thereby casting

\footnotetext{
${ }^{11}$ Notice, that estimates of the career patterns of female economists are based on a rather small number of observations and need, therefore, to be interpreted with caution. Moreover, it is worth pointing out that even though the point estimates of the life cycle polynomials differ, this difference is statistically not significant. This might also be due to the small number of female economists.

${ }^{12}$ We estimated our baseline regression (column 1 ) also with ten year cohort dummies as well as a polynomial specification of the cohort effects. The results are in line with the results presented here.
} 
doubt on the applicability of this estimator. This caveat probably does not come as a surprise, considering the count data character of the publication process. Since, however, the Tobit estimates are in accordance with to the other estimates this may be interpreted as a sign of the robustness of our results. Nevertheless, we now proceed to employ more robust econometric techniques.

\subsection{Quantile regressions and cohort-specific life cycles}

The semi-parametric censored quantile regression estimator for censored data developed by Powell (1984 and 1986) is more robust than the estimators used above because it allows the error terms to be heteroscedastic and non-normally distributed. Since we have to reject both of the hypotheses we now employ this estimator. We estimate the 75,80 , 85, 90 and 95 percentiles. The results are depicted in the first panel of Figure 2 and the estimates are presented in Table II for the 85 and 95 percentiles: 


\begin{tabular}{|c|c|c|c|c|c|c|c|}
\hline \multirow[t]{2}{*}{ Table II } & \multicolumn{2}{|c|}{$\begin{array}{c}\text { Censored } \\
\text { Quantile regressions }\end{array}$} & \multicolumn{5}{|c|}{$\begin{array}{c}\text { Censored Quantile Regressions: } \\
\text { Estimates by Cohort (0.85- Percentile) }\end{array}$} \\
\hline & \multicolumn{2}{|c|}{$0.85 \quad 0.95$} & $1969-74$ & $1975-80$ & $1981-86$ & $1987-92$ & 1993-98 \\
\hline $\begin{array}{l}\mathrm{T} \\
\mathrm{T}^{2} / 10 \\
\mathrm{~T}^{3} / 100 \\
\mathrm{~T}^{4} / 1000 \\
\mathrm{~T}^{5} / 10000\end{array}$ & $\begin{array}{l}2.1676^{* * *} \\
(14.49) \\
-2.8526^{* * *} \\
(10.04) \\
1.6422^{* * *} \\
(7.61) \\
-0.4266^{* * *} \\
(6.16) \\
0.0404^{* * *} \\
(5.15)\end{array}$ & $\begin{array}{l}2.8923^{* * *} \\
(19.21) \\
-3.7942^{* * *} \\
(10.03) \\
2.1279^{* * *} \\
(6.51) \\
-0.5312^{* * *} \\
(4.84) \\
0.0482^{* * *} \\
(3.83)\end{array}$ & $\begin{array}{l}0.853^{* * *} \\
(4.13) \\
-0.864^{* * *} \\
(3.51) \\
0.350^{* * *} \\
(3.18) \\
-0.050^{* * *} \\
(3.04)\end{array}$ & $\begin{array}{l}0.586^{* * *} \\
(4.06) \\
-0.333^{* *} \\
(2.39) \\
0.054 \\
(1.53)\end{array}$ & $\begin{array}{l}1.519^{* * *} \\
(6.57) \\
-1.340^{* * *} \\
(4.83) \\
0.353^{* * *} \\
(3.85)\end{array}$ & $\begin{array}{l}2.176^{* * *} \\
(5.36) \\
-2.000^{* * *} \\
(3.03) \\
0.450 \\
(1.60)\end{array}$ & $\begin{array}{l}2.707^{* * *} \\
(7.21) \\
-2.121^{* * *} \\
(4.88)\end{array}$ \\
\hline C6974 & 0.0250 & $-0.8927 * *$ & & & & & \\
\hline C7580 & $\begin{array}{l}1.1243^{* * *} \\
(4.52)\end{array}$ & $\begin{array}{l}2.456^{* * * *} \\
(3.28)\end{array}$ & & & $\begin{array}{l}0.887 \\
(1.36)\end{array}$ & & \\
\hline C8186 & $\begin{array}{l}3 . .5250^{* * *} \\
(11.10)\end{array}$ & $\begin{array}{l}5.2910^{* * *} \\
(7.22)\end{array}$ & & & $\begin{array}{l}1.387 \\
(1.87)^{*}\end{array}$ & & \\
\hline C8792 & $\begin{array}{l}5.0167 * * * \\
(10.96)\end{array}$ & $\begin{array}{l}7.9526 * * * \\
(9.31)\end{array}$ & & & $\begin{array}{l}2.248 \\
(2.87)\end{array}$ & & \\
\hline С9398 & $\begin{array}{l}6.8719 * * * \\
(12.80)\end{array}$ & $\begin{array}{l}9.4926 * * * \\
(13.17)\end{array}$ & & & $\begin{array}{l}2.559 * * * \\
(3.25)\end{array}$ & & \\
\hline MICRO & $\begin{array}{l}6.3848 * * * \\
(14.59)\end{array}$ & $\begin{array}{l}9.2334 * * * \\
(12.46)\end{array}$ & & & $\begin{array}{l}6.877 * * * \\
(12.38)\end{array}$ & & \\
\hline MACRO & $\begin{array}{l}4.4841^{* * *} \\
(12.41)\end{array}$ & $\begin{array}{l}4.8795^{* * *} \\
(8.48)\end{array}$ & & & $\begin{array}{l}4.804^{* * *} \\
(10.44)\end{array}$ & & \\
\hline PUBLIC ECONOMICS & $\begin{array}{l}3.8014^{* * *} \\
(10.72)\end{array}$ & $\begin{array}{l}4.2405^{* * *} \\
(8.35)\end{array}$ & & & $\begin{array}{l}4.610 * * * \\
(10.40)\end{array}$ & & \\
\hline ECONOMETRICS & $\begin{array}{l}3.1507^{* * * *} \\
(8.32)\end{array}$ & $\begin{array}{l}2.7574 * * * \\
(5.60)\end{array}$ & & & $\begin{array}{l}3.882^{* * *} \\
(8.34)\end{array}$ & & \\
\hline FEMALE & $\begin{array}{l}-2.491 * * * \\
(6.26)\end{array}$ & $\begin{array}{l}-3.0367 * * * \\
(3.89)\end{array}$ & & & $\begin{array}{l}-2 . .032 * * * \\
(5.27)\end{array}$ & & \\
\hline CONSTANT & $\begin{array}{l}-7.870^{* * *} \\
(14.84)\end{array}$ & $\begin{array}{l}-5.6269 * * * \\
(8.99)\end{array}$ & & & $\begin{array}{l}-5.691 * * * \\
(8.08)\end{array}$ & & \\
\hline Observations & 16003 & 16003 & & & 13555 & & \\
\hline
\end{tabular}

Notes: Absolute t-values in parentheses. We excluded researchers which never had a publication. For the cohort regressions we also excluded researchers with a Ph.D. before 1969. Estimates are based on the Fitzenberger (1997) algorithm. Standard Errors bootstrapped using Bilias et al. (2000) method (200 replications).

The Figure reveals that the most productive researchers are much more productive than the less productive ones; more precisely, the line-up of individual research productivities (from low to high) is heavily skewed to the right. This feature (which is reflected in the figure by the fact that the distance between the percentile lines becomes increasingly 
larger) is a stylized fact of all distributions of research productivities. More interesting is perhaps the fact that this skewness appears to be pretty stable over career time. Most important for our argument is however that our main results gleaned from the less robust estimation models presented in the previous subsection are confirmed.

Figure 2: Censored Quantile regressions
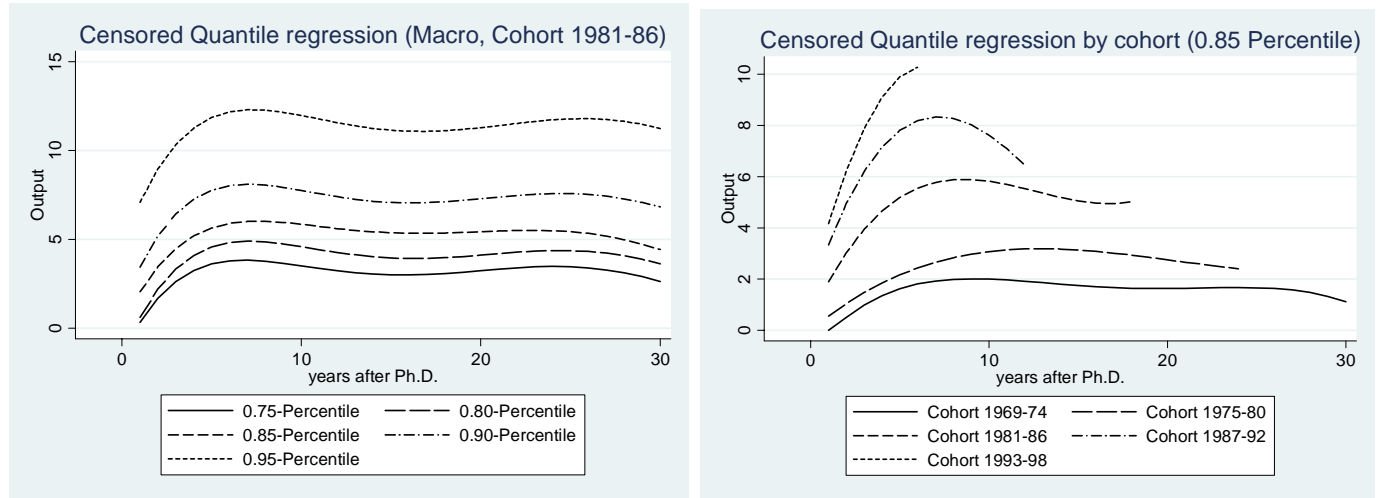

Until now we used the whole sample of economists to estimate the shape of the productivity life cycles, allowing only for cohort-specific constant terms. It would, however, not be farfetched to assume that over the last thirty-five years the shape of the lifecycles may have been subject to significant changes. As we have argued above, increased competition between researchers or other institutional changes may have influenced research behavior. To account for this possibility we allow for separate time polynomials for each cohort using censored quantile regressions. The results are documented in Table II, columns 3-7, and in the second panel of Figure 2. This figure reveals that the productivity lifecycles of younger cohorts are - as far as one can tell from 
the initial phases of these cycles - more hump-shaped than those of earlier cohorts. ${ }^{13}$ The research behavior of the younger German economists thus appears to be much more in line with the predictions of the standard human capital approach to explaining changes in labor productivity than the research track record their older peers. This evidence supports the hypothesis that the German academic environment has become increasingly competitive over the last 35 years, with the consequence that the academics who entered the market later were forced to adopt a more and more narrow optimizing behavior if they wanted to be successful. As a result, the younger economists' research behavior corresponds more closely to the predictions of the incentive-centered human capital approach to explaining labor market outcomes.

So far we have not exploited the panel structure of our dataset. To account for the multitude of fixed effects which are specific to the individual researchers, we use a quantile estimator due to Honoré (1992). It is semi-parametric and therefore robust with respect to distributional assumptions and generalizes our results in the sense that we now explicitly take individual specific fixed effects into account. The estimates are presented in Table $3 .^{14}$ As can be seen in Figure 3, the shape of the estimated career-time polynomial compares well with the pooled quantile estimates presented in Table $2 .{ }^{15}$ Our previous results thus pass this robustness test with flying colors.

\footnotetext{
${ }^{13}$ In an earlier paper (see Rauber and Ursprung, 2006) we have identified the same pattern of cohort-specific lifecycles by including cohort-specific career-time polynomial in a standard Tobit regression.

${ }^{14}$ We used the PANTOB estimation program written by Bo Honoré and J. Campbell.

${ }^{15}$ Note, however, that the levels of the cycles cannot be interpreted because they are governed by the individual effects. The stacking of the curves in Figure 3 therefore serves only to illustrate the results.
} 


\begin{tabular}{|c|c|c|c|c|c|}
\hline \multicolumn{6}{|c|}{ Table III : Semiparametric Fixed Effects estimation (Honoré 1992) } \\
\hline & $1969-74$ & $1975-80$ & $1981-86$ & $1987-92$ & $1993-98$ \\
\hline $\begin{array}{l}\mathrm{T} \\
\mathrm{T}^{2} / 10 \\
\mathrm{~T}^{3} / 100 \\
\mathrm{~T}^{4} / 1000\end{array}$ & $\begin{array}{l}2.430 * * * \\
(4.18) \\
-2.472^{* * *} \\
(4.10) \\
0.989^{* * *} \\
(3.94) \\
-0.136^{* * *} \\
(3.82)\end{array}$ & \begin{tabular}{|l}
$1.696^{* * *}$ \\
$(5.09)$ \\
$-1.764^{* * *}$ \\
$(4.19)$ \\
$0.722^{* * *}$ \\
$(3.10)$ \\
$-0.102^{* * *}$ \\
$(2.31)$
\end{tabular} & $\begin{array}{l}3.031^{* * *} \\
(3.99) \\
-3.915^{* * *} \\
(2.89) \\
1.945^{* * *} \\
(2.18) \\
-0.331^{*} \\
(1.69)\end{array}$ & $\begin{array}{l}3.342 * * * \\
(7.37) \\
-3.587 * * * \\
(5.88) \\
1.089 * * * \\
(4.50)\end{array}$ & $\begin{array}{l}3.844^{* * *} \\
(8.90) \\
-4.775^{* * *} \\
(5.24) \\
1.715^{* * *} \\
(2.68)\end{array}$ \\
\hline $\begin{array}{l}\text { Observations } \\
\text { Value of Loss Function }\end{array}$ & $\begin{array}{l}\text { Quadratic L } \\
\text { random sea }\end{array}$ & $\begin{array}{l}\text { oss Functiol } \\
\text { Irch }\end{array}$ & $\begin{array}{c}13555 \\
104162.908 \\
\text { n; Starting va }\end{array}$ & lues found $t$ & hrough \\
\hline
\end{tabular}

Notes: Absolute t-values in parentheses. We excluded researchers who never published or received their Ph.D. before 1963.

Figure 3: Semiparametric Fixed effects estimation (Honoré, 1992)

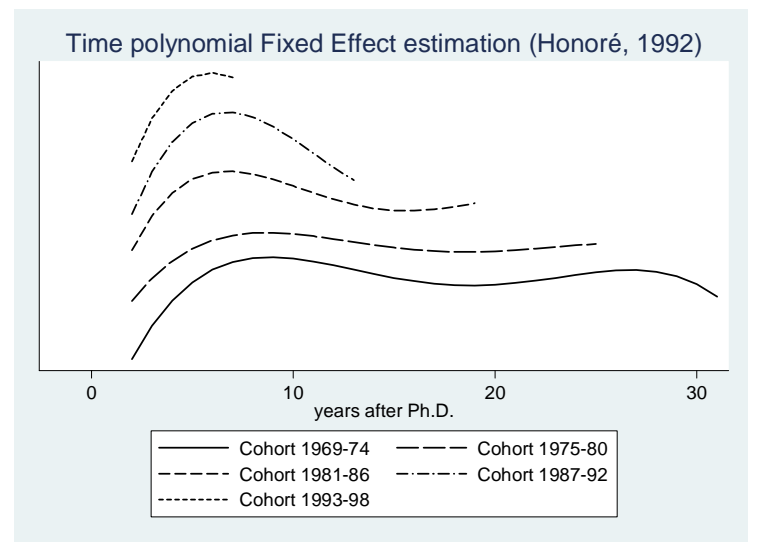

At this stage a caveat is called for. Over the last thirty-five years the publication habits in the German economics profession may have changed. If it is true that monographs and articles in collected volumes have become less important research outlets as compared to journal publications, this substitution process might be responsible for the large cohort effects we observe in our empirical analysis. 
There is some evidence that the ratio of the number of active researchers and the number of journals slightly decreased over the last thirty years. ${ }^{16}$ The crucial question thus is whether younger economists indeed publish significantly more than their older peers or whether the cohort effects identified above are simply due to dramatic changes in the publication habits. To disentangle these effects we follow the general approach advocated by Rodgers (1982): Since identification by functional form is rather arbitrary and even small specification errors might lead to large differences in the estimates, we make use of a proxy variable for the prevailing publication habits.

To pin down the development of publication habits we roughly estimated the cocitation patterns of journal articles vis-à-vis other journal articles, articles in collected volumes, and monographs. ${ }^{17}$ The percentage share of journal citations in journal articles indeed increases over time. The estimated time trend is depicted in Figure $4 .^{18}$ Since our measure of research output is truncated we cannot apply a trend correction before estimation. Such a procedure would not allow correcting for the marginal density of publication incidence. We therefore apply our correction after estimation, i.e. we rescale the estimated research life cycles of each cohort by multiplying each year's estimated output by the ratio of the journal citation share in 2004 (which amounts to 60\%) and the journal citation share in the respective year. We thereby obtain a correction which

\footnotetext{
${ }^{16}$ Goyal, van der Leu and Moraga-Gonalez (2004) count the number of authors in EconLit: 33770 in the 70's, 48608 in the 80's and 81217 in the 90's. The number of journals indexed in EconLit in 1975, 1985 and 1995 is 200, 311 and 535, respectively. Calculating author per journal ratios yields: 168.85, 156.3 and 151.

${ }^{17}$ We based our investigation on a random sample of articles published in the American Economic Review, The European Economic Review, Public Choice and the Jahrbücher für Nationalökonomie und Statistik an calculated the citation-shares of journals, monographs, collected volumes, working papers, and statistical sources for the years 1969, 1978, 1987, 1996 and 2005. In total we classified 8824 citations.

${ }^{18}$ We approximated the original time series by fitting a quadratic polynomial.
} 
represents an upper limit of the substitution of research output towards the learned journals.

Figure 4: Historical time and cohort effects
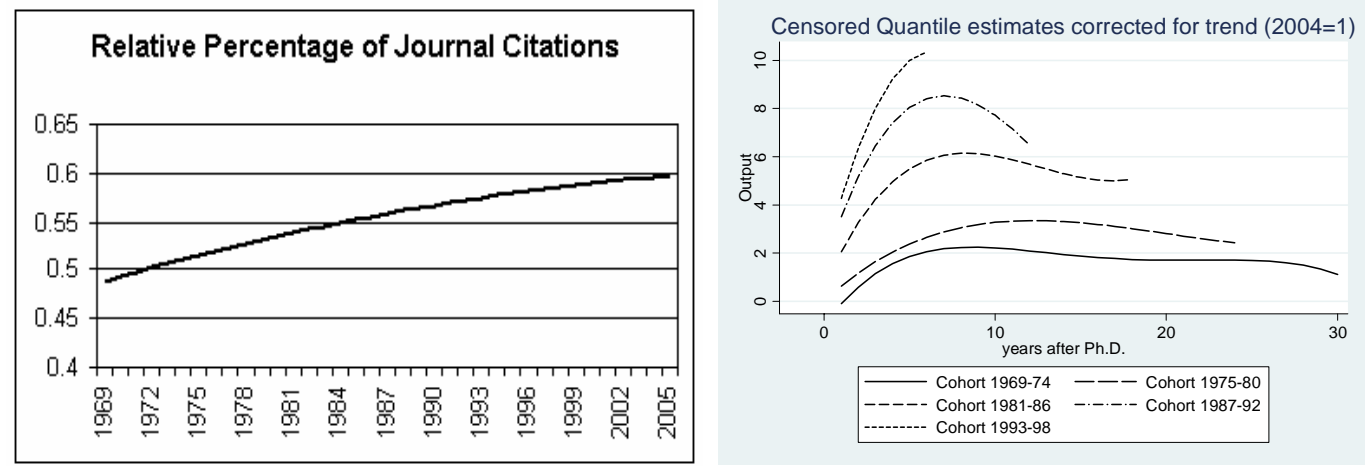

The result of our correction exercise is depicted in the second panel of Figure 4. Even though we biased our test against the hypothesis of significant cohort effects in research productivity, this hypothesis survives the test easily. In other words, the younger German economists are so much more productive in producing journal articles than their older peers that the implied superiority in research productivity cannot be contested by any reasonable correction for the observed changes in publication habits.

\subsection{Ability-specific life cycles}

We now turn to analyzing to what extent the life cycles vary across groups of different academic achievements. This focus distinguishes our study from all those studies that investigate only a subset of highly productive individuals. Since we deal with many different types of researchers, we now relax the constraint of a uniform career-time polynomial for all individuals. We do so by applying a mixture model in the first stage of 
the hurdle model. ${ }^{19}$ The combined model performs two tasks: first, it endogenously allocates each researcher to an appropriate (ability-) group and, second, it estimates the life cycle parameters for each group. The likelihood function of the mixture model has the following appearance:

$$
f\left(y_{i} \mid w_{i}\right)=\sum_{k=1}^{K} \operatorname{Pr}\left(C_{i}=k\right) \operatorname{Pr}\left(Y_{i}=y_{i} \mid C_{i}=k, W_{i}=w_{i}\right)
$$

$W_{i}=\left(w_{i 1} \ldots, w_{i T}\right)$ represent all time-dependent covariates which are captured by a time polynomial up to order four. The probability of group affiliation is specified by a generalized logit function and the conditional output density follows a censored normal distribution. We estimated the mixture model separately for each cohort and assigned individuals to two different groups. ${ }^{20}$ In each cohort, the model clearly identifies two different groups: journeymen researchers and accomplished researchers. About two thirds of all individuals are assigned into the journeymen group whereas one third is assigned into the accomplished group.

Since two different types of economists are identified, we re-estimated our hurdle model - this time allowing for separate lifecycles for the two groups. The results are depicted in Figure 5.

\footnotetext{
${ }^{19}$ A different method which yields similar results is applied in Rauber and Ursprung (2006).

${ }^{20}$ Cohort specific estimation ensures that group assignment is not driven by the cohort effects which we identified above. We used the SAS estimation procedure TRAJ which maximizes the joint likelihood of the mixture model. For estimation details see Jones, Nagin and Roeder (2001). We settled here for two groups because more groups would give rise to an insufficient number of members in some of the groups and because such a division is also indicated by the Bayesian Information Criterion.
} 


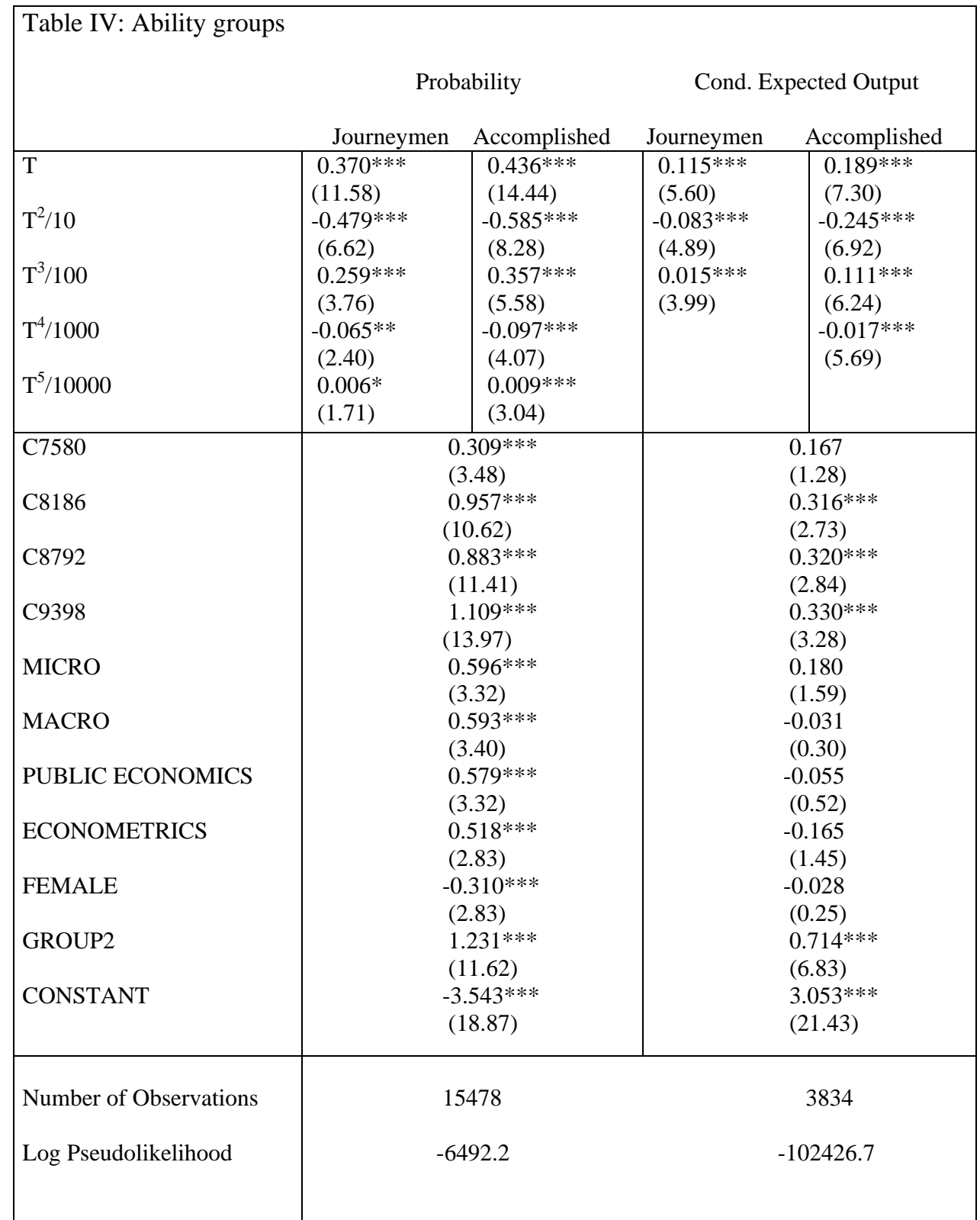

Notes: Grouping was carried out using a mixture model as described in Section 3.3. Absolute tvalues in parentheses, based upon a clustering robust Variance-Covariance Matrix. We excluded researchers with a Ph.D. before 1969 due to missing data at the onset of the career. 
Figure 5: Ability specific regressions
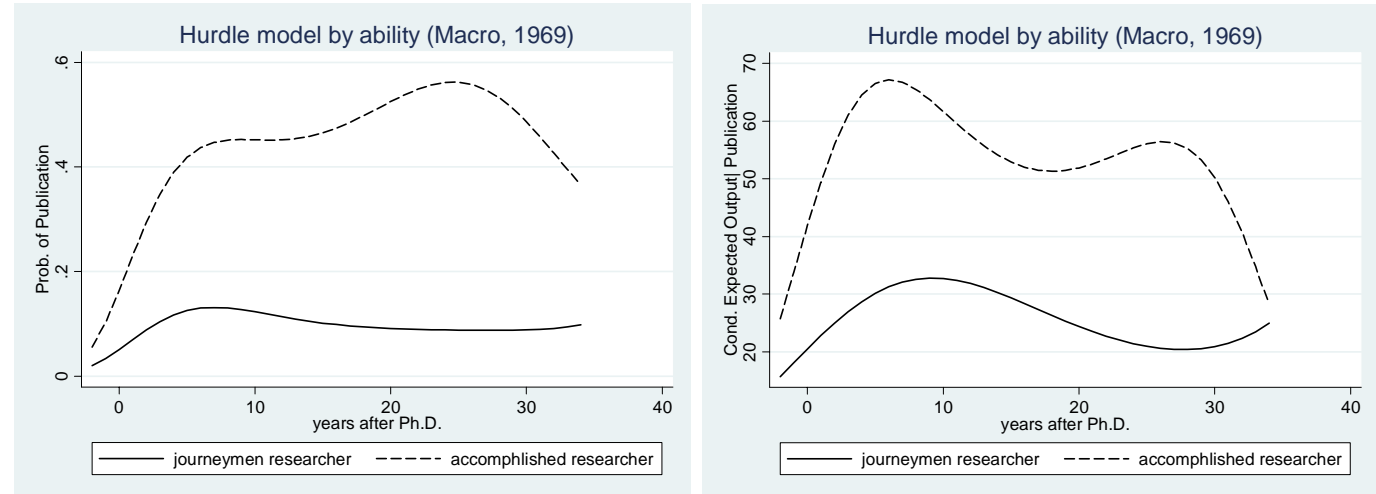

We observe that the probability of publication as well as the conditional output clearly differs across the two groups. More productive researchers appear to have incentives to publish a steady stream of papers until the end of their career. Reputation or intrinsic motivation might be a reason. Moreover, the conditional output of the accomplished researchers stabilizes at a much higher level than the output of the journeymen researchers. Needless to say, that these differences cannot be identified by simply focusing on a subset of highly productive individuals.

\section{An exercise in deconstruction: Quality, quantity and co-authorship}

Up to now we have treated research productivity as measured by the CLpn index as a preordained unit of account. The shapes of the identified life cycles suggest however that the constituent parts of this productivity measure might follow quite different patterns that cannot be uncovered by an investigation at the aggregate level. In this section we therefore deconstruct the employed index and focus our investigation on the constituent parts thereof, namely on quality, quantity and the number of collaborators. In order to 
identify life-cycle patterns in these constituent parts of research productivity we "deconstruct" the density of our dependent variable in the following way:

$f(Y=E N C Q)=f_{E}\left(E \mid \theta_{E}\right) \cdot f_{N}\left(N \mid \theta_{N}, E=1\right) \cdot f_{C}\left(C \mid \theta_{C}, N, E=1\right) \cdot f_{Q}\left(Q \mid \theta_{Q}, C, N, E=1\right)$

The first factor (E) on the RHS captures whether economist $i$ has been involved in producing research output in year t or not. The second marginal density $(\mathrm{N})$ represents the number of publications given that at least one publication has been produced in t. The third factor (C) denotes the average quantitative contribution per article (number of pages per coauthor) and the fourth factor (Q) the average quality of the articles authored or coauthored by economist i in year t. An exemplary deconstruction of the score can be found in the Appendix.

The first column in Table V presents the regression for the number of authored or co-authored journal articles. As can be seen from the first panel of Figure 6, this number reaches a first maximum approximately seven years after German economists are granted their doctoral degrees and remains thereafter more or less constant for about ten years. 


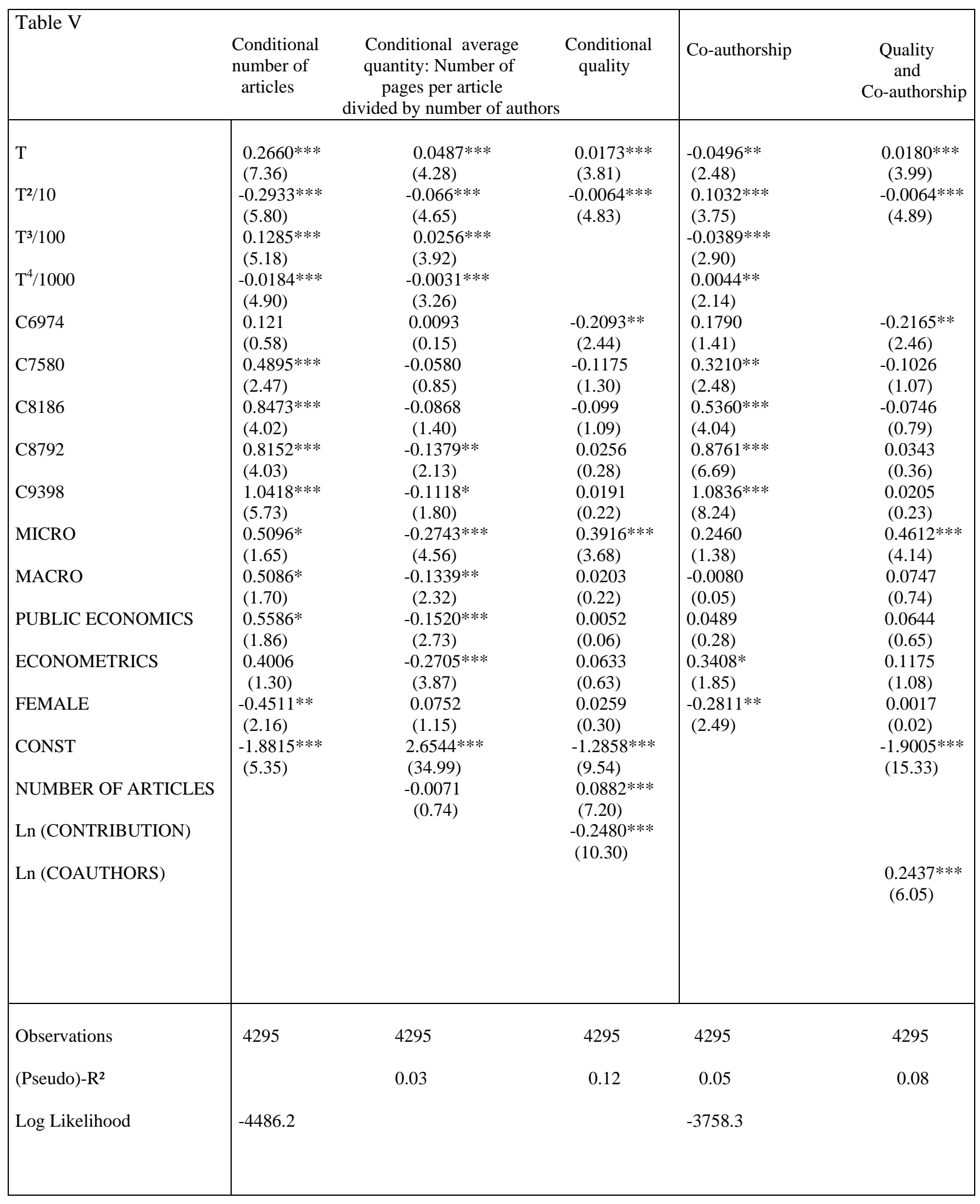

Notes: Absolute t-value in parentheses, based upon a clustering robust Variance-Covariance Matrix. Estimation methods: (1): Zero-Truncated Poisson regression; (2): OLS on Logarithm of average contribution; (3), (5): OLS on Logarithm of average quality; (4) Ordered Probit 
Figure 6: Density Deconstruction
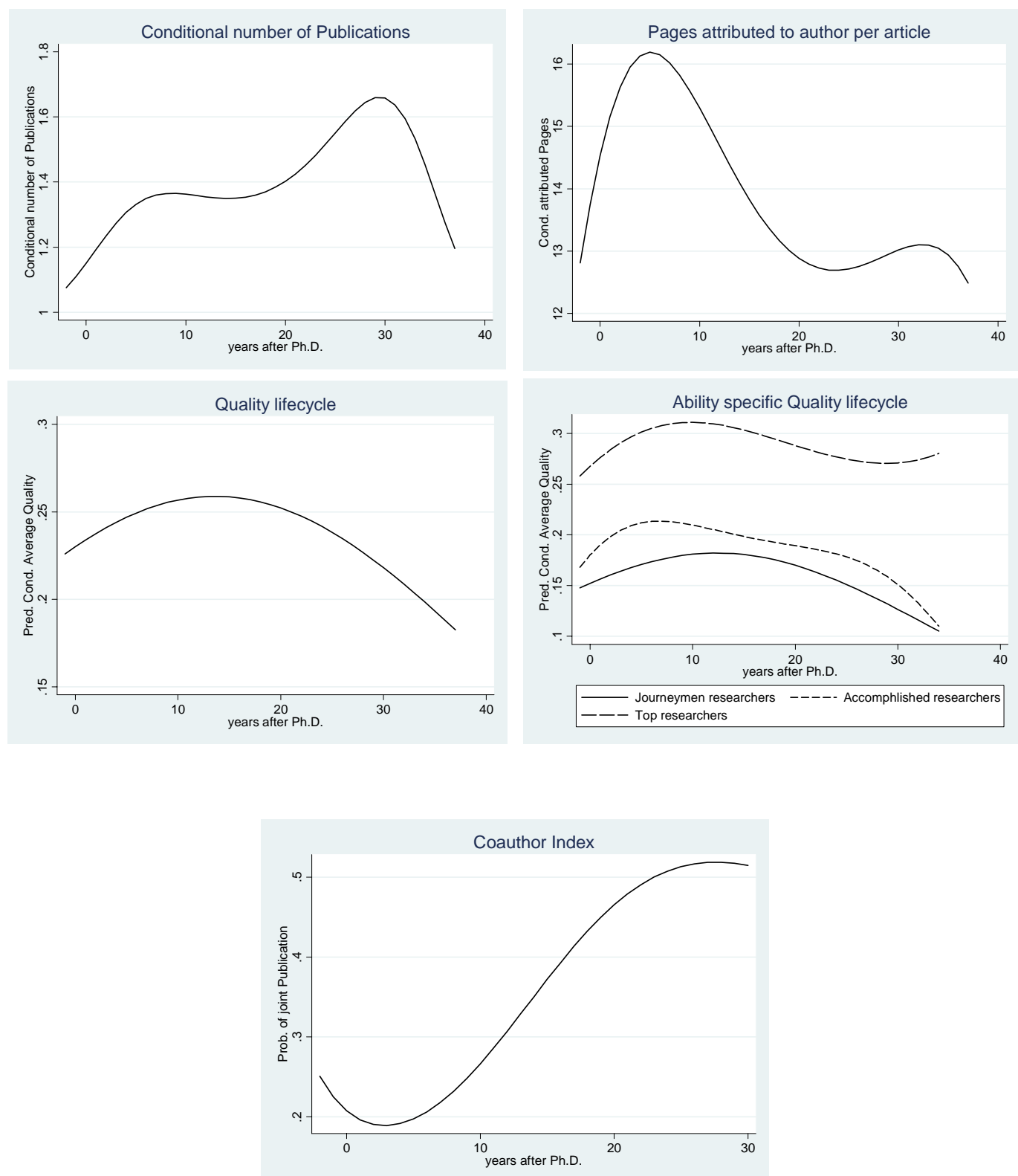

Around the middle of the career the number of publications begins to increase again and continues to do so until about five years before retirement. We will show below that this second increase is due to a higher co-authorship incidence of older economists. Whereas young economists appear to write most of their articles by themselves (and therefore publish only a few), older researchers tend to publish together with co-authors and therefore put their names on a larger number of papers. This increase in co-authorships 
might be either due to network effects, or to the fact that senior economists more often write joint papers with the doctoral students they supervise.

In the second column of Table $\mathrm{V}$ our dependent variable is the logarithm of average research quantity (number of pages per article divided by the number of authors). Explanatory variables are our usual independent variables and the number of articles authored or coauthored. An inspection of the second panel of Figure 6 reveals that the average contribution per paper declines after an early career peak. The increased incidence of co-authorships of course contributes to the decline after the first peak. It thus transpires that at the beginning of their careers, economists, conceivably for reputation reasons, focus their research activity on relatively few projects that are pursued without collaborators, whereas at later stages they tend to spread themselves wider and prefer to engage more in collaborative research endeavors. The minor peak that can be found before retirement may be an artifact of the econometric specification, but it may also reflect a certain leaning of older economists to busy themselves with sweeping themes that require a lot of space to be developed.

The third and arguably most important constituent part of our measure of research productivity is (average) quality. Our regression results for the average research-quality variable are summarized in the third column of Table V. We regress the logarithm of the average quality on our independent variables, the number of articles published and the logarithm of the average research quantity. ${ }^{21}$

${ }^{21}$ The density of the quality variable is centered around the discrete steps of the underlying weighting scheme. To check for the robustness of the results we also transformed our quality measure into a variable that can assume six different values that correspond to the original journal quality weights. We then applied an ordered probit model to estimate the underlying quality lifecycle. The results are in line with the linear regression results presented here. 
As far as the "average economist" is concerned, it is fair to say that not only overall research productivity but also average research quality follows a hump-shaped lifecycle: the average quality sharply increases at the very beginning of the career as the budding economists become increasingly accomplished, but begins to decline already around the twelfth career year when the average German economist is about 42 years old. Since the average economist's lifecycle in research productivity is relatively flat as compared to the identified lifecycle in research quality, this indicates that quantity is substituted for quality as the economist's career progresses. In order to check whether this substitution process is ability specific, we estimated ability specific quality lifecycles by using a procedure advocated by Goodwin and Sauer (1995): We defined quintile ranks according to average lifetime productivity within each three years cohort of researchers. We then assigned each researcher the appropriate rank and included for the first, second, and the bottom three ranks separate career-time polynomials as well as researcher fixed effects in the regression. ${ }^{22}$ In contrast to the endogenous grouping presented before, this procedure allows us to focus specifically on highly accomplished researchers. The results presented in panel 4 of Figure 6 indicates that top-performers are able to keep up research quality much more than their less gifted peers: the relative drop between the career years 10 and 30 amounting to about $13 \%$ for the top researcher and $30 \%$ for the accomplished and journeymen researchers. ${ }^{23}$ These results lend strong support to our notion that when measuring research productivity over the lifecycle it is imperative to include all types of journals; employing bibliometric approaches that focus on a subset of prime-rate journals

\footnotetext{
${ }^{22}$ We bundled the bottom groups because of the high degree of censoring and because our main focus is on the high rate publishers. We excluded the oldest cohort because for these researchers we do not observe the first six post Ph.D. years and our ability indicator would therefore be biased. ${ }^{23}$ Oster and Hamermesh (1998) arrive at a similar result.
} 
cannot detect patterns of research behavior that involve substitution of quantity for quality.

We now, finally, return to our hypothesis maintaining that co-authorship becomes more attractive as the average economist's career progresses. ${ }^{24}$ To explore this hypothesis in more detail, we construct a co-author index measuring each economist's average number of collaborators (including him- or herself), by using the number of pages as the respective weight for each journal article published in the respective year. The regression explaining the number of co-authors is presented in the forth column of Table V. The implied life-cycle is depicted in the fifth panel of Figure 6. This figure reveals that the number of co-authors is relatively high for graduate students and reaches a minimum about three years after economists are conferred their doctoral degrees. Afterwards the number of co-authors steadily increases over the whole life-cycle. This piece of evidence points towards network advantages of more mature economists and, as far as the odd early-career twist is concerned, to a high incidence of collaborative efforts between graduate students and supervisors.

The last regression presented in Table $\mathrm{V}$ re-estimates the impact of our explanatory variables on the average quality of research without conditioning on the length or number of articles. As compared to the former regression we also included here our index of the average number of co-authors. It transpires that quality indeed depends on the number of collaborators: working with other scholars appears to increase research quality.

${ }^{24}$ There is a small literature on the topic of co-authorship; see, for example, McDowell and Smith (1992), Hollis (2001), Laband (2002), and Sutter and Kocher (2004). 


\section{Conclusions}

In investigating the careers of German academic economists we have come across two characteristics that we regard to be essential for our understanding of the profession. First, we discovered that the pattern of research productivity over the life cycle is codetermined by economic incentives and by sociological factors. The influence of the economic incentives is reflected in the hump-shape of the identified life cycles, the sociological factors show up in the marked cohort effects. As compared to the lifecycles of their American peers, the life cycles of German economists turn out to be flatter and the level of research productivity appears to depend much more on cohort specific factors. We do, however, not interpret these finding as evidence supporting the hypothesis that the American profession is mainly driven by economic incentives and the German profession by sociological factors. Our results simply reflect the fact the academic environment in Germany has changed much more dramatically over the period of our investigation than the science system in the United States.

The second uncovered characteristic of the economics profession that deserves special attention is the fact that lifecycles in research productivity are ability and gender specific. Studies that attempt to identify the research behavior of the "representative" economist miss a large part of the story. The economics profession is very heterogeneous and neglecting this heterogeneity may give rise to severe misinterpretations. It is worth emphasizing that this heterogeneity in ability not only affects the variance of the level of individual research productivity (this we have known for a long time from various ranking exercises), heterogeneity also has distinct effects on the dynamic dimension of research productivity, i.e. on the shape of the individual life cycles. The ability-induced 
variation in life cycle patterns is especially striking when one compares life cycles in the quality of research.

As mentioned above, the fact that the life cycles in research productivity turn out to be rather flat in the German profession lends some support to the sociological imprinting hypothesis. This does, however, not imply that economic incentives are of second-order importance. Career hurdles, for example, may well provide incentives which have a great deal of influence: since we find early career peaks that appear to coincide with the timing of the only career hurdle in the traditional German science system, our results are certainly compatible with the existence of pre-tenure peaks and post-tenure kinks, and thus with the results derived by Backes-Gellner and Schlinghoff (2004). Moreover, we have found strong evidence suggesting that the marked increase in average research productivity across cohorts has been accompanied by a significant change in the career profiles: the research-productivity lifecycles of the youngest German economists closely resemble the lifecycles of their Anglo-Saxon peers. This implies that the observed process of catching-up with the most productive research systems is about to be accomplished not by changing the behavior of the profession at large but rather by letting the new generation of economists grow into an academic environment in which the behavior of the researchers is guided by economic incentives. Economic incentives thus do not appear to change accustomed behavioral patterns; incentives do however influence the behavior of the incoming generations of scientists. We thus arrive at the conclusion that research behavior is co-determined by economic and sociological factors. If one attempts to make a national science system catch up with the frontier of research, a time span of two generations appears to be a minimum: one generation to transfer and 
implement the new spirit accompanied by the requisite institutional reforms, and one generation to overcome the acquired habits.

Finally, we would like to highlight a management consequence that arises from this study. Since life-cycle and cohort effects turn out to represent major determinants of research production in Germany, this information should be taken into account not only on the occasion of evaluating individual researchers, but also when one attempts to rank university departments, the reason being that the exogenous age and cohort structure of the departments significantly affects the observed research productivity. It therefore appears to be obvious that these effects should be deducted from the gross amount of research produced if one attempts to fairly represent a department's research standing. Even though adjustments for career-age have been made in the ranking literature (see, for example, Combes and Linnemer, 2003), these adjustments were up to now based on an ad hoc reckoning. Our empirical study provides the kind of information that would have to be used in more sophisticated rankings. Our companion paper (2006) presents a new ranking methodology which incorporates these lifecycle and cohort aspects. 


\section{References}

Backes-Gellner, U. and A. Schlinghoff (2004): Careers, incentives and publication patterns of US and German (business) economists, http://papers.ssrn.com/sol3/papers.cfm?abstract_id=616822

Baser, O. and E. Pema (2004): Publications over the academic life-cycle: Evidence for academic economists, Economics Bulletin 1, 1-8.

Bell, J. and J. Seater (1978): Publishing performance: Departmental an individual, Economic Inquiry 16, 599-615.

Bilias Y., S. Chen and Z.Ying (2000): Simple Resampling methods for censored Regression Quantiles, Journal of Econometrics 99, 373-386.

Combes, P. and L. Linnemer (2003): Where are the economists who publish? Publication concentration and rankings in Europe based on cumulative publications, Journal of the European Economic Association 1, 1250-1308.

Coupé, T. (2003): Revealed performances: Worldwide rankings of economists and economics departments, 1990-2000, Journal of the European Economic Association 1, 1309-1345.

Coupé, T. (2004): What do we know about ourselves? On the economics of economics, Kyklos 57, 197-215.

Coupé, T., V. Smeets and F. Warzynski (2003): Incentives in economic departments: Testing Tournaments, Working Paper 03-25, Aarhus School of Business.

Coupé, T., V. Smeets and F. Warzynski (2006): Incentives, sorting and productivity along the career: Evidence from a sample of top economists, Journal of Law, Economics, and Organization 22, 137-167.

Dnes, A. and N. Garoupa (2005): Academic tenure, post-tenure effort, and contractual damages, Economic Inquiry 43, 832-839.

Fitzenberger, B. (1997): A Guide to Censored Quantile Regressions, in G.S. Maddala and C.R. Rao (eds.), Handbook of Statistics, Volume 15, 405-437.

Frey, B. (2007): Evaluierungen, Evaluierungen ... Evaluitis, Perspektiven der Wirtschaftspolitik 8, 207-220.

Goodwin, T.H. and R.D. Sauer (1995): Life cycle productivity in academic research: Evidence from cumulative publication histories of academic economists, Southern Economic Journal, 728-743.

Goyal, S. and van der Leu, M. and J. L. Moraga-Gonzales (2004): Economics: An emerging small world? CESifo Working Paper No. 1287.

Grimes, P.W. and C.A. Register (1997): Career Publications and academic job rank: Evidence from the class of 1968, Journal of Economic Education 28, 82-92.

Hartley, J.E., J.W. Monks and M.D. Robinson (2001): Economists’ publication patterns, The American Economist 45, 80-85. 
Hollis, A. (2001): Co-authorship and the Output of Academic Economists, Labour Economics 8, 503-30.

Honoré, B.E.(1992): Trimmed Lad and Least Squares Estimation of Truncated and Censored Regression Models with Fixed Effects, Econometrica 60, 533-565.

Hutchinson, E.B. and T.L. Zivney (1995): The publication profile of economists, Journal of Economic Education, 59-79.

Jones, B.L. Nagin, D.S. and Roeder K. (2001): A SAS Procedure Based on Mixture Models for Estimating Development Trajectories, Sociological Methods \& Research 29, 374-393.

Kalaitzidakis, P., Mamuneas, T. and T. Stengos (2003): Rankings of academic Journals and Institutions in economics, Journal of the European Economic Association 1, 1346-1366.

Kenny, L. and R. Studley (1995): Economists' salaries and lifetime productivity, Southern Economic Journal 65, 382-393.

Laband, D. (2002): Contribution, Attribution and the Allocation of Intellectual Property Rights: Economics versus Agricultural Economics, Labour Economics 9, 125-31.

McDowell, J. and J. Smith (1992): The Effect of Gender-Sorting on Propensity to Coauthor: Implications for Academic Promotion, Economic Inquiry 30, 68-82.

Moore, W., R. Newman and G. Turnbull (2001): Reputational capital and academic pay, Economic Inquiry 39, 663-671.

Oster, S.M. and D.S. Hamermesh (1998): Aging and productivity among economists, Review of Economics and Statistics 80, 154-156.

Pagan, A., and F. Vella: Diagnostic Tests for Models Based on Individual Data: A Survey, Journal of Applied Econometrics, 4, Supplement, 1989, pp. 29-59.

Pohlmeier W. and V. Ulrich (1995): An Econometric Model of the Two-Part Decisionmaking Process in the Demand for Health Care, The Journal of Human Resources 30, 339-361.

Powell, J.L. (1984): Least Absolute Deviations Estimation for the Censored Regression Model, Journal of Econometrics 25, 303-325.

Powell J. L. (1986): Censored Regression Quantiles, Journal of Econometrics 32, 143155

Rauber M. und H. Ursprung (2006): Evaluation of researchers: A life cycle analysis of German academic economists, CESifo Working Paper No. 1673.

Rodgers W. L. (1982): Estimable Fuctions of Age, Period, and Cohort Effects, American Socilogical Review 47, 774-787.

Skirbekk, V. (2004): Age and Individual Productivity: A Literature Survey, In G. Feichtinger, ed., Vienna Yearbook of Population Research, Vienna, Austrian Academy of Sciences Press: 133-153

Stephan, P. (1996): The economics of science, Journal of Economic Literature 34, 11991235. 
Sutter, M. and M. Kocher (2001): Tools for evaluating research output: Are citationbased rankings of journals stable? Evaluation Review 25, 555-566.

Sutter, M. and M Kocher (2004): Patterns of co-authorship among economics departments in the U.S., Applied Economics 36, 327-333.

Wooldridge, J. (2002): Econometric Analysis of Cross Section and Panel Data. The MIT Press Cambridge M.A.

Van Dalen, H. (1999): The golden age of Nobel economists, American Economist, 19-35 


\section{Appendix}

\section{Exemplary Density Deconstruction}

Assume two papers are published in year t, one together with a coauthor (40 pages, quality $\frac{1}{12}$ ) and the other one without co-author (15 pages, quality $\frac{1}{2}$ ). The Output $(Y)$ is then calculated as:

$$
\mathrm{Y}_{\mathrm{it}}=\frac{1}{2} \cdot 40 \cdot 0.08+1 \cdot 15 \cdot 0.5=9.1
$$

The number of pages attributed to the author is denoted by

$$
\mathrm{P}_{\mathrm{it}}=\frac{1}{2} \cdot 40+1 \cdot 15=35
$$

We then simply divide $\mathrm{Y}_{\text {it }}$ through $\mathrm{P}_{\text {it }}$ to arrive at the average quality for year $\mathrm{t}$ :

$$
Q_{i t}=\frac{9.1}{35}=0.26
$$

To compute the average (quantitative) contribution per paper we divide Pages through the number (here 2) of articles written. This is a measure of the average contribution (measured in pages; here 17.5) to each paper authored or co-authored. 


\section{CESifo Working Paper Series}

for full list see www.cesifo-group.org/wp

(address: Poschingerstr. 5, 81679 Munich, Germany, office@cesifo.de)

2028 Jarko Fidrmuc, Neil Foster and Johann Scharler, Labour Market Rigidities, Financial Integration and International Risk Sharing in the OECD, June 2007

2029 Bernardina Algieri and Thierry Bracke, Patterns of Current Account Adjustment Insights from Past Experience, June 2007

2030 Robert Dur and Hein Roelfsema, Social Exchange and Common Agency in Organizations, June 2007

2031 Alexander Libman and Lars P. Feld, Strategic Tax Collection and Fiscal Decentralisation: The Case of Russia, June 2007

2032 Øystein Foros, Hans Jarle Kind and Greg Shaffer, Resale Price Maintenance and Restrictions on Dominant Firm and Industry-Wide Adoption, June 2007

2033 Jan K. Brueckner and Kurt Van Dender, Atomistic Congestion Tolls at Concentrated Airports? Seeking a Unified View in the Internalization Debate, June 2007

2034 Viet Do and Ngo Van Long, International Outsourcing under Monopolistic Competition: Winners and Losers, June 2007

2035 Nadia Fiorino and Roberto Ricciuti, Determinants of Direct Democracy, June 2007

2036 Burkhard Heer and Alfred Maussner, Inflation and Output Dynamics in a Model with Labor Market Search and Capital Accumulation, June 2007

2037 Konstantinos Angelopoulos, Jim Malley and Apostolis Philippopoulos, Public Education Expenditure, Growth and Welfare, June 2007

2038 Maarten Bosker, Steven Brakman, Harry Garretsen and Marc Schramm, Adding Geography to the New Economic Geography, June 2007

2039 Steffen Henzel, Oliver Hülsewig, Eric Mayer and Timo Wollmershäuser, The Price Puzzle Revisited: Can the Cost Channel Explain a Rise in Inflation after a Monetary Policy Shock?, July 2007

2040 Rosario Crinò, Service Offshoring and White-Collar Employment, July 2007

2041 Carsten Hefeker and Michael Neugart, Labor Market Regulation and the Legal System, July 2007

2042 Bart Cockx and Muriel Dejemeppe, Is the Notification of Monitoring a Threat to the Unemployed? A Regression Discontinuity Approach, July 2007

2043 Alfons J. Weichenrieder, Profit Shifting in the EU: Evidence from Germany, July 2007 
2044 Annika Alexius and Bertil Holmlund, Monetary Policy and Swedish Unemployment Fluctuations, July 2007

2045 Axel Dreher, Jan-Egbert Sturm and Jakob de Haan, Does High Inflation Cause Central Bankers to Lose their Job? Evidence Based on a New Data Set, July 2007

2046 Guglielmo Maria Caporale and Luis A. Gil-Alana, Long Run and Cyclical Dynamics in the US Stock Market, July 2007

2047 Alessandro Balestrino, It is a Theft but not a Crime, July 2007

2048 Daniel Becker and Michael Rauscher, Fiscal Competition in Space and Time: An Endogenous-Growth Approach, July 2007

2049 Yannis M. Ioannides, Henry G. Overman, Esteban Rossi-Hansberg and Kurt Schmidheiny, The Effect of Information and Communication Technologies on Urban Structure, July 2007

2050 Hans-Werner Sinn, Please Bring me the New York Times - On the European Roots of Richard Abel Musgrave, July 2007

2051 Gunther Schnabl and Christian Danne, A Role Model for China? Exchange Rate Flexibility and Monetary Policy in Japan, July 2007

2052 Joseph Plasmans, Jorge Fornero and Tomasz Michalak, A Microfounded Sectoral Model for Open Economies, July 2007

2053 Vesa Kanniainen and Panu Poutvaara, Imperfect Transmission of Tacit Knowledge and other Barriers to Entrepreneurship, July 2007

2054 Marko Koethenbuerger, Federal Tax-Transfer Policy and Intergovernmental PreCommitment, July 2007

2055 Hendrik Jürges and Kerstin Schneider, What Can Go Wrong Will Go Wrong: Birthday Effects and Early Tracking in the German School System, July 2007

2056 Bahram Pesaran and M. Hashem Pesaran, Modelling Volatilities and Conditional Correlations in Futures Markets with a Multivariate t Distribution, July 2007

2057 Walter H. Fisher and Christian Keuschnigg, Pension Reform and Labor Market Incentives, July 2007

2058 Martin Altemeyer-Bartscher, Dirk T. G. Rübbelke and Eytan Sheshinski, Policies to Internalize Reciprocal International Spillovers, July 2007

2059 Kurt R. Brekke, Astrid L. Grasdal and Tor Helge Holmås, Regulation and Pricing of Pharmaceuticals: Reference Pricing or Price Cap Regulation?, July 2007

2060 Tigran Poghosyan and Jakob de Haan, Interest Rate Linkages in EMU Countries: A Rolling Threshold Vector Error-Correction Approach, July 2007 
2061 Robert Dur and Klaas Staal, Local Public Good Provision, Municipal Consolidation, and National Transfers, July 2007

2062 Helge Berger and Anika Holler, What Determines Fiscal Policy? Evidence from German States, July 2007

2063 Ernesto Reuben and Arno Riedl, Public Goods Provision and Sanctioning in Privileged Groups, July 2007

2064 Jan Hanousek, Dana Hajkova and Randall K. Filer, A Rise by Any Other Name? Sensitivity of Growth Regressions to Data Source, July 2007

2065 Yin-Wong Cheung and Xing Wang Qian, Hoarding of International Reserves: Mrs Machlup's Wardrobe and the Joneses, July 2007

2066 Sheilagh Ogilvie, 'Whatever Is, Is Right'?, Economic Institutions in Pre-Industrial Europe (Tawney Lecture 2006), August 2007

2067 Floriana Cerniglia and Laura Pagani, The European Union and the Member States: Which Level of Government Should Do what? An Empirical Analysis of Europeans' Preferences, August 2007

2068 Alessandro Balestrino and Cinzia Ciardi, Social Norms, Cognitive Dissonance and the Timing of Marriage, August 2007

2069 Massimo Bordignon, Exit and Voice. Yardstick versus Fiscal Competition across Governments, August 2007

2070 Emily Blanchard and Gerald Willmann, Political Stasis or Protectionist Rut? Policy Mechanisms for Trade Reform in a Democracy, August 2007

2071 Maarten Bosker and Harry Garretsen, Trade Costs, Market Access and Economic Geography: Why the Empirical Specification of Trade Costs Matters, August 2007

2072 Marco Runkel and Guttorm Schjelderup, The Choice of Apportionment Factors under Formula Apportionment, August 2007

2073 Jay Pil Choi, Tying in Two-Sided Markets with Multi-Homing, August 2007

2074 Marcella Nicolini, Institutions and Offshoring Decision, August 2007

2075 Rainer Niemann, The Impact of Tax Uncertainty on Irreversible Investment, August 2007

2076 Nikitas Konstantinidis, Gradualism and Uncertainty in International Union Formation, August 2007

2077 Maria Bas and Ivan Ledezma, Market Access and the Evolution of within Plant Productivity in Chile, August 2007 
2078 Friedrich Breyer and Stefan Hupfeld, On the Fairness of Early Retirement Provisions, August 2007

2079 Scott Alan Carson, Black and White Labor Market Outcomes in the $19^{\text {th }}$ Century American South, August 2007

2080 Christian Bauer, Paul De Grauwe and Stefan Reitz, Exchange Rates Dynamics in a Target Zone - A Heterogeneous Expectations Approach, August 2007

2081 Ana Rute Cardoso, Miguel Portela, Carla Sá and Fernando Alexandre, Demand for Higher Education Programs: The Impact of the Bologna Process, August 2007

2082 Christian Hopp and Axel Dreher, Do Differences in Institutional and Legal Environments Explain Cross-Country Variations in IPO Underpricing?, August 2007

2083 Hans-Werner Sinn, Pareto Optimality in the Extraction of Fossil Fuels and the Greenhouse Effect: A Note, August 2007

2084 Robert Fenge, Maximilian von Ehrlich and Matthias Wrede, Fiscal Competition, Convergence and Agglomeration, August 2007

2085 Volker Nitsch, Die Another Day: Duration in German Import Trade, August 2007

2086 Kam Ki Tang and Jie Zhang, Morbidity, Mortality, Health Expenditures and Annuitization, August 2007

2087 Hans-Werner Sinn, Public Policies against Global Warming, August 2007

2088 Arti Grover, International Outsourcing and the Supply Side Productivity Determinants, September 2007

2089 M. Alejandra Cattaneo and Stefan C. Wolter, Are the Elderly a Threat to Educational Expenditures?, September 2007

2090 Ted Bergstrom, Rod Garratt and Damien Sheehan-Connor, One Chance in a Million: Altruism and the Bone Marrow Registry, September 2007

2091 Geraldo Cerqueiro, Hans Degryse and Steven Ongena, Rules versus Discretion in Loan Rate Setting, September 2007

2092 Henrik Jacobsen Kleven, Claus Thustrup Kreiner and Emmanuel Saez, The Optimal Income Taxation of Couples as a Multi-Dimensional Screening Problem, September 2007

2093 Michael Rauber and Heinrich W. Ursprung, Life Cycle and Cohort Productivity in Economic Research: The Case of Germany, September 2007 